\title{
DISSIDÊNCIAS EPISTEMOLÓGICAS À BRASILEIRA: UMA CARTOGRAFIA DAS TEORIZAÇÕES QUEER NA PESQUISA EM EDUCAÇÃO
}

\author{
DiLTON RIBEIRO COUTO JUNIOR \\ Fernando Altair Pocahy \\ Universidade do Estado do Rio de Janeiro (UERJ), Rio de Janeiro, \\ Rio de Janeiro, Brasil
}

\begin{abstract}
Resumo: A proposta deste trabalho é mapear os usos e impactos dos efeitos epistemológicos das contribuições queer na produção de conhecimento em educação no Brasil. Para isso, buscamos traçar um plano (provisório) que possa indicar algo da complexa trama por onde essas experimentações epistemológicas enredam-se no contexto da produção acadêmica, do campo de estudos de gênero e sexualidade, autoproclamada e/ou interpelada dissidente. Com isso, interessa-nos aqui promover interlocuções cartográficas a partir de nossas vivências enquanto sujeitos latino-americanos vivências marcadas pelo entrecruzamento de diversos marcadores sociais de identidade e diferença que nos constituem e nos impulsionam a (re)pensar nossas experiências cotidianas.
\end{abstract}

Palavras-chave: Gênero. Sexualidade. Epistemologias queer. Educação.

1 TRÂNSITOS DE UMA TEORIA: INICIANDO UMA CONVERSA

Encontrei [na "teorização"] um lugar onde eu podia imaginar futuros possíveis, um lugar onde a vida podia ser diferente. Essa experiência "vivida" de pensamento crítico, de reflexão e análise se tornou um lugar onde eu 
trabalhava para explicar a mágoa e fazê-la ir embora. Fundamentalmente, essa experiência me ensinou que a teoria pode ser um lugar de cura'.

bell hooks

A feminista negra estadunidense bell hooks, ao comentar sobre as mágoas de sua infância, denunciando a norma patriarcal vivenciada no âmbito familiar, ressalta a importância das teorizações para se (re)pensar um futuro outro, para se (re)pensar a própria experiência social cotidiana. $A$ teoria em si não é intrinsecamente libertadora e/ou restaurativa, mas adquire essa dimensão na medida em que passa a ser direcionada para esse objetivo (hooks, 2013). As teorizações nos convidam a analisar as relações sociais através de diferentes pontos de vista, desafiando-nos a questionar convenções e práticas naturalizadas. Com isso, buscamos na teoria formas outras de se (re) pensar corpos, gêneros e sexualidades em suas posições dissidentes, uma vez que esses sujeitos encontram-se na mira dos olhares marcados por normas e ideais regulatórios - não somente nos seus efeitos de dor, mas também em suas condições de possibilidade de reinvenção de si, como exterioridade constitutiva por onde temos a chance de nos transformarmos em outra coisa que não aquilo tudo o que paralisa e produz morte social.

Com Butler (2017, p 44) aprendemos que "se uma vida não é tratada como se sua perda fosse terrível, então sua perda já está incorporada na noção de vida. É por isso que uma vida tem de ser considerada primeiramente como digna de luto para ser tratada plenamente como vida". Dito isso, partimos do pressuposto de que todas as vidas merecem ser vividas, embora muitas ainda estejam constantemente na mira dos ataques sociais, impulsionados e alimentados por discursos fundamentalistas que buscam eliminar qualquer tentativa de que corpos, gêneros e sexualidades possam ser experimentadosfabricados para além dos já conhecidos e restritos modelos binários. Se por um lado as normas regulatórias se manifestavam através das diversas práticas de vigilância (POCAHY, 2007), por outro lado é também na fronteira das zonas de abjeção que movimentos e estratégias de resistência se estabelecem. Onde há poder, lá está a resistência, proclama Foucault (2014).

Com este texto buscamos acompanhar movimentos/experimentações teórico-metodológicos/as que permitem cruzar as fronteiras epistemológicas², enfrentando o regime hetero[CIS]centrado ${ }^{3}$ (PRECIADO, 2014) a partir de teorizações que vêm/vieram sendo informadas e/ou impactadas pelas perspectivas queer (no sentido em que elas informam ou potencializam práticas de insubordinação diante dos cânones teóricos e $(\mathrm{m})$ seus regimes de verdade). As insurgências teórico-metodológicas que se emparelham 
às chamadas políticas queer buscam formular estratégias de resistência, desconfiam dos estabelecidos e movimentam-se por "brechas e formas de transgredir as práticas e discursos sociais já instaurados e naturalizados e que mantém intacta uma concepção de mundo sintonizada com a ótica heteronormativa" (COUTO JUNIOR; OSWALD, 2016, p. 124).

A expressão "teoria queer" foi mencionada pela primeira vez em 1990, nos EUA, durante uma conferência proferida pela pesquisadora feminista italiana Teresa De Lauretis. Durante sua fala, De Lauretis buscava fomentar uma crítica aos estudos gays e lésbicos da época, denunciando o essencialismo identitário e colocando em xeque a compreensão das identidades sexuais e de gênero sob a perspectiva de uma matriz binária (MISKOLCl, 2009; LUGARINHO, 2010). Dessa forma, a teoria queer possibilitou a construção de uma proposta de política pós-identitária cujo alvo não seria "propriamente as vidas ou os destinos de homens e mulheres homossexuais, mas sim a crítica à oposição heterossexual/homossexual, compreendida como a categoria central que organiza as práticas sociais, o conhecimento e as relações entre os sujeitos" (LOURO, 2001, p. 549). O que está em jogo nas apostas movimentadas nas políticas queer é a exposição das contingências e dos limites da heteronormatividade, a partir do argumento central de que corpos, gêneros e sexualidades são construções históricas, sociais e culturais (COUTO JUNIOR, 2016).

Queer é interpelação pejorativa utilizada em países de língua inglesa, demarcando diferença, assinalando os desviantes da norma heterossexual. Traduzido para o português, queer significa "bizarro", "estranho", "veado", "bicha,"'sapatão", dentre outros. O termo, "com toda sua carga de estranheza e de deboche, é assumido por uma vertente dos movimentos homossexuais [nos EUA] precisamente para caracterizar sua perspectiva de oposição e de contestação" (LOURO, 2001, p. 546) às heteronormas. O sentido injurioso do queer foi estrategicamente adotado para denunciar as experiências da abjeção sofridas pelos grupos que integravam as chamadas minorias sexuais. Esses grupos passaram a ressignificar o termo pejorativo, transformando-o "numa forma orgulhosa de manifestar a diferença" (PEREIRA, 2006, p. 469, grifo $d x$ autorx).

Desde sua emergência político-epistemológica na década de 1990, a teoria queer vem sendo enunciada de diversas formas. Reapropriações da expressão "teoria queer" revelam sua plasticidade na produção acadêmica voltada, mas não restrita, ao campo de estudos de gênero e sexualidade. "Estudos queer","políticas queer", "teorias queer" (no plural) (CAMARGO, 2008), "abordagens queer" (COELHO, 2009) e "epistemologias queer" (POCAHY, 
2016; COUTO JUNIOR; OSWALD; POCAHY, 2017) são algumas possibilidades enunciativas dadas a essa irreverente teoria. Tais expressões nem sempre são utilizadas meramente como formas sinônimas à expressão "teoria queer", mas surgem pela necessidade de se ampliar o entendimento sobre o quanto o queer não caberia apenas na condição de teoria, mas estaria articulado a outras formas de compreender o mundo para além do contexto acadêmico-universitário-científico.

Somando-se a isso, o termo queer também é empregado como verbo por diversxs pesquisadorxs ${ }^{4}$ de países que se comunicam através do idioma inglês, português e espanhol. O uso do "queerizar" (cuja grafia em português é a mesma adotada pelxs estudiosxs que escrevem em espanhol) é feito, ainda que timidamente, por pesquisadorxs como Trujillo (2015), Couto Junior e Oswald (2016), Borba (2015) e Peres et al. (2014), sendo que o uso do "queering" (inglês) pode ser evidenciado nos trabalhos de Butler (1993), Seidman (1994) e Bryson e Castell (1993), para citar alguns exemplos. Lewis et al. (2017) propõem ainda o termo "cu-irizar" como substituição às expressões "queerizar", "estranhar" etc., buscando"sublinhar a originalidade e o valor das nossas produções e epistemologias locais, e seu potencial de des-norte-ar os estudos queer, sem esquecer o contexto pós-colonial de desigualdade geopolítica no qual nós [latinos], e nossas teorias, nos encontramos" (2017, p. 6, grifo dxs autorxs). Dessa forma, os (des)arranjos teórico-metodológicos engendrados pelos estudos queer demonstram o quanto suas reflexões originárias no Norte global, ao"respingarem" de diferentes formas nas Ciências Humanas e Sociais, vêm produzindo profundas disputas políticas no campo de estudos de gênero e sexualidade latino-americano.

O que conhecemos hoje no Brasil por teoria queer emergiu há algumas décadas como resposta dos movimentos norte-americanos de gays, trans e lésbicas aos impactos da aids 5 no país (PELÚCIO, 2014a). Inicialmente concebida como o"câncer gay", a aids trouxe como consequência a renovação do discurso de ódio promovido pelos ideais homofóbicos, reforçando a onda conversadora já observada em diversos setores sociais (LOURO, 2001). Ainda que o vírus hiv ou a doença da aids estivessem sob os olhos atentos da sociedade, eram as relações sexuais entre pessoas do mesmo sexo as compreendidas como forte ameaça à perpetuação da cultura e espécie humana (MISKOLCl, 2014). Naquele contexto, o mandato presidencial de Ronald Reagan (1981-1989) coincidiu com o alastramento da epidemia da aids nos EUA, com Reagan recusando-se a fornecer apoio e auxílio às vítimas da doença (MISKOLCl, 2011). Em contrapartida ao pânico sexual e social criado em torno da epidemia da aids, foi desencadeado o aumento da participação 
política de diversos pesquisadores, que passaram a contribuir com reflexões teóricas responsáveis pela consolidação do que compreendemos atualmente como teoria queer (MISKOLCI, 2014).

Articulada inicialmente no Norte global, a teoria queer vem se constituindo como uma resposta irreverente das minorias sociais às normas regulatórias de gênero. A abordagem teórica do pensamento queeré ancorada nos Estudos Culturais norte-americanos e na corrente pós-estruturalista da filosofia, com muitas contribuições advindas das obras História da sexualidade I: a vontade de saber, de Michel Foucault, e Gramatologia, de Jacques Derrida (MISKOLCl, 2009). Entretanto, diferentemente dos EUA, cuja demanda social e cujos debates no âmbito dos diferentes movimentos propiciaram o fortalecimento de argumentos que tornaram possível a idealização de uma teoria queer, a chegada dessa teoria ao Brasil ocorreu por meio do âmbito universitário (PELÚCIO, 2014a).

Reiteramos o quanto é, de certa forma, contraditório traçar uma cronologia da emergência das teorias queer, uma vez que a constituição dessas apostas teórico-militantes envolveu uma gama de origens e influências diversas, bebendo principalmente das reflexões tecidas no âmbito das pesquisas acadêmicas e dos ativismos políticos (LEWIS et al., 2017). Dito isso, cabe investigar quais vêm sendo os percursos traçados pelas epistemologias queer, que encontraram um espaço potente nas pesquisas acadêmicas através do "agenciamento de novos planos de experimentação ético-estéticopolíticos na produção do conhecimento" (POCAHY, 2016, p. 12).

Sobre a emergência e os desdobramentos da teoria queer na América Latina, Miskolci (2014) argumenta que tem sido notório o movimento unidirecional desta teoria: inventada no Norte, suas reflexões são, geralmente, meramente incorporadas à produção acadêmica latino-americana. $\mathrm{O}$ fluxo de produção de conhecimento segue, portanto, a lógica do movimento norte-sul, com os países do Sul colocados na posição de meros interlocutores silenciosos e invisíveis do "monólogo teórico euro-americano" (MISKOLCl, 2014, p. 58). O movimento unidirecional norte-sul percorrido por essa teoria evidencia claramente o Norte global como autor/produtor de teorias, com os países do Sul se constituindo geralmente como meros "receptores" $e^{\text {"importadores" }}$ de teorias que acabam muitas vezes desconsiderando suas marcas e riquezas locais (LEWIS et al., 2017).

Em encontro a essa direção, Pereira (2015) mostra que a teoria queer formulada no Norte global "viaja ao Sul, com os desafios, os perigos e as potencialidades que as viagens ensejam. Por isso, pode haver a tentação de simplesmente aplicá-la, como se aquele termo (queer) e a subversão que 
provoca [...] não atuassem também em deslocamentos" (2015, p. 413-414, grifo $\mathrm{dx}$ autorx). Neste sentido, já não caberia o uso estratégico do termo queer no Brasil, uma vez que essa expressão sequer está "na boca do povo" brasileiro. Caminhamos amparados pela ideia de que a tradução imediata da teoria queer para a língua portuguesa não é possível, restando-nos então reinterpretar e reelaborar essa expressão considerando as inúmeras marcas culturais presentes no contexto brasileiro (LUGARINHO, 2010).

Desde a popularização da teoria queer, em 2001, no Brasil com o texto de Guacira Lopes Louro (2001), diversxs pesquisadorxs brasileiros vêm expondo os limites de uma teoria formulada no Norte global e, ao mesmo tempo, encontrando alternativas que possibilitem (re)pensar o termo queer ao Sul da linha do Equador. (Re)pensar o queer no contexto brasileiro significa (re)criar epistemologias atentas aos contextos e marcas culturais locais através da formulação de abordagens interseccionais que abarquem os diferentes marcadores sociais, como gênero, sexualidade, raça, classe e localização geográfica. Dessa forma, uma investigação afetada pelo queer "permite-nos pensar nos termos de insurgências linguísticas, outras semióticas do desejo e do prazer, outros modos de pensar" (POCAHY, 2016, p. 16) e de pesquisar.

A proposta deste trabalho, fruto de pesquisa de pós-doutorado em andamento ${ }^{6}$, é cartografar os usos e impactos dos efeitos epistemológicos das contribuições queer para o campo dos estudos de gênero e sexualidade em educação no Brasil. Para isso, flertamos com epistemologias teóricas que visam deslocar o olhar para o Sul da linha do Equador, buscando questionar os ideais de "uma moralidade burguesa, medicalizada e marcadamente eurocentrada" (PELÚCIO, 2014a, p. 28). Não há que se negligenciar que o movimento unidirecional norte-sul percorrido pela teoria queer nos auxiliou na formulação da crítica sobre quais são os países reconhecidos e legitimados a produzir teorizações, e quais aqueles que permanecem na condição de "meros receptores" de teorias que, comumente, desconsideram marcas e tradições locais.

Nesse sentido, cabe a máxima foucaultiana de que o poder é produtivo. Argumentamos a favor dessa crítica e questionamos ainda o quanto se faz necessário que as teorizações produzidas ao Sul da linha do Equador possam caminhar "com as próprias pernas" a partir da tessitura de reflexões que abarquem os diferentes marcadores sociais de identidade e diferença. Consequentemente, já não estaríamos mais discutindo somente a partir de uma teoria queer do Norte, mas amparados também com epistemologias produzidas no Sul, potentes na investigação das experiências e dissidências de gênero e sexualidade latino-americanas. 


\section{CONSIDERAÇõES SOBRE OS (DES)CAMINHOS INVESTIGATIVOS}

$\mathrm{O}(\mathrm{s})$ (des)caminhos metodológicos engendrados na realização do panorama dos trabalhos que dialogam com a teoria queer propiciaram que encontrássemos na cartografia um princípio ético-estético-político que nos aproximou das produções teórico-metodológicas realizadas por pesquisadorxs brasileirxs. Essas produções, cujas reflexões encontram-se situadas em diferentes espaços-tempos, vêm nos auxiliando na investigação dos efeitos das teorizações queer no campo de pesquisa educacional. Através da prática cartográfica, nossa aposta de investigar as tensões éticoestético-políticas disparadas pelos desdobramentos do queer na pesquisa em educação emerge da necessidade de acompanhar o entrecruzamento dos múltiplos fluxos do saber, produzidos por pontos de vista fundamentados em suas próprias epistemologias.

Ao assumirmos uma intencionalidade cartográfica para investigar os efeitos das teorizações queer, buscamos uma "estratégia de análise crítica e ação política, olhar crítico que acompanha e descreve relações, trajetórias, formações rizomáticas, a composição de dispositivos, apontando linhas de fuga, ruptura e resistência" (PRADO FILHO; TETI, 2013, p. 47). Esse modo nos convida a problematizar as próprias enunciações e jogos de saber-poder produzidos no âmbito científico, principalmente no que se refere à forma como vimos reconhecendo e legitimando determinados conhecimentos acadêmicos, não raramente relegados ao campo do "inquestionável".

A cartografia emerge da crítica aos modos tradicionais de produzir conhecimento, ou seja, do questionamento às pesquisas cujos métodos encontram-se ancorados no paradigma moderno (razão, objetividade, neutralidade) (ZAMBENEDETTI; SILVA, R., 2011). Dessa forma, o percurso a ser tra(n)çado pelxs pesquisadorxs no ofício de cartografar seu campo revela a especificidade de um princípio metodológico que não prima por uma objetividade única, mas pela singularidade com que o objeto de estudo é abordado/analisado (PRADO FILHO; TETI, 2013). Corroborando essa perspectiva, Zambenedetti e R. Silva (2011) argumentam que a prática cartográfica constitui um conjunto de ferramentas de análise criadas "sem a intenção de erigi-las em modelos baseados em regras e procedimentos prédefinidos, capazes de serem aplicados, replicados e generalizados" (p. 454).

Segundo Suely Rolnik (1987), as teorias são como cartografias. A aposta $\mathrm{dx}$ autorx nos permite experimentações: tomamos aqui as cartografias como planografias de acontecimentos, mapas que se desenham em movimento, composições de fluxos de conhecimento e redes de afecção, traçados de redes complexas de saber-poder, mapeamentos de processos 
de subjetivação ou daquilo que interpela alguém a uma determinada forma de agir-pensar o/no mundo. Com isso, reconhecemos que os cotidianos são "formados por relações, carregados de qualidades heterogêneas, que se comunicam e se ligam entre si. Espaço em rede, constituído por linhas e pontos, atravessado por relações e carregado de qualidades e intensidades" (PRADO FILHO; TETI, 2013, p. 54).

A problematização cartográfica apresenta como um de seus focos centrais a investigação dos "jogos de verdade e de enunciação, jogos de objetivação e subjetivação, modos de sujeição e assujeitamento, produção de corpos morais, sexuais, produtivos, estetizações e produções de si mesmo, formas de resistência, práticas de liberdade" (PRADO FILHO; TETI, 2013 , p. 56). Dessa forma, agir cartograficamente significa abrir mão de métodos cristalizados, da previsibilidade e do controle e, consequentemente, permanecer aberto à proposição de novos caminhos metodológicos na produção de conhecimentos (ZAMBENEDETTI; SILVA, R., 2011).

Artigos publicados em periódicos científicos (indexados pela CAPES $^{7}$ ), livros, capítulos de livros, teses, dissertações e textos publicados em anais de eventos constituíram o campo material analisado para se mapear os efeitos das teorizações queer na produção nacional voltada, mas não restrita, ao campo da educacional. Foram selecionados cerca de vinte trabalhos publicados desde 2001, uma vez que o referido ano foi um marco na repercussão da teoria queer no Brasil, o que ocorreu através da publicação do artigo de Louro (2001) na Revista Estudos Feministas, amplamente difundido e discutido entre pesquisadorxs do campo de estudos de gênero e sexualidade (MISKOLCI, 2011; SOUZA; BENETTI, 2015).

As entradas de problematização que elaboramos nessa cartografia (tomando aqui os trabalhos como entradas, fios que nos conectam a uma rede de fruição epistemológica) serão apresentadas no item seguinte. Essas entradas focalizaram a análise de trabalhos disponibilizados na internet, uma vez que reconhecemos o quanto a rede mundial de computadores constituise hoje como o principal meio de se fornecer ampla visibilidade às pesquisas que vêm sendo produzidas em cada região do país.

3 O QUeER NO NORTE, E O QUe(eR) AO SUl DA LINHA DO EQUador? ACOMPANHANDO (ALGUNS) FLUXOS

As repercussões da teoria queer na produção acadêmica brasileira apontam para o engajamento político e ético cada vez maior de pesquisadorxs que buscam criar epistemologias decoloniais. A decolonização consiste na possibilidade de desprendimento do eurocentrismo, tanto de sua 
lógica quanto de seu aparato, impulsionando-nos a pesquisar/vivenciar/ experimentar outras "histórias e teorias, abrir-se aos Outros encobertos pela lógica da colonialidade - esses Outros tornados menores, abjetos, desqualificados" (PEREIRA, 2015, p. 422). Assim, colocar em prática o ato de descolonizar teorias implica nosso compromisso político-ético de (re) pensar o lugar social ocupado pelos países periféricos, denunciando o quanto as experiências culturais dissidentes são geralmente invisibilizadas e desqualificadas pelos colonizadores.

A partir das experiências dissidências de gênero e sexualidade que vêm sendo produzidas ao Sul da linha do Equador, reconhecemos a necessidade de fomentar discussões teóricas que, longe de serem meramente incorporadas do Norte global, possam ser desencadeadas a partir de epistemologias sintonizadas com nosso lugar de origem que, não raramente, é social e geograficamente reconhecido como o "cu do mundo" (PELÚCIO, 2014a, p. 78). Interessa-nos dialogar a partir de nossas vivências enquanto sujeitos latino-americanos - vivências marcadas pelo entrecruzamento de diversos marcadores sociais de identidade e diferença que nos constituem e nos impulsionam a (re)pensar nossas próprias experiências cotidianas como sendo periféricas, mas também insurgentes, desobedientes.

Movimentamo-nos através das epistemologias queer porque defendemos "um jeito de pensar e de ser que não aspira o centro nem o quer como referência; um jeito de pensar e de ser que desafia as normas regulatórias da sociedade" (LOURO, 2013, p. 7-8). Pensar a partir das insurgências epistemológicas queer, articulando-as e recriando-as à luz do contexto sociocultural brasileiro, é um caminho para potencializar a produção de uma crítica voltada aos processos discursos que conferem aos corpos, gêneros e sexualidades o selo de uma normalidade que é social e culturalmente construída. Segundo reforça Pocahy $(2016$, p. 12), os esforços dos "movimentos de dissidência de gênero e sexualidade vêm produzindo efeitos importantes e decisivos em termos de rupturas epistemológicas" na produção do conhecimento.

Buscamos planos de experimentação teóricos engendrados pelas epistemologias queer para (re)pensar "o sentido da pesquisa como (re) inventora dos problemas sobre nosso tempo, forçando a passagem de outras epistemologias de mundo (que não apenas as epistemologias científicas)" (POCAHY, 2016, p. 17). Com isso, parece-nos imprescindível o ato de estranhar discursos (LOURO, 2013), acompanhar movimentos que intentam profanar teorias, ressignificando a ideia de que nenhum texto é incontestável ou sagrado, 
mas sempre tecido por meio de reflexões que buscam, de forma provisória, analisar interpretativamente determinados contextos e práticas sociais.

Entendemos o queer como uma abordagem discursivo-desconstrucionista interessada nos efeitos que o dispositivo da sexualidade e os ideais regulatórios de gênero e a racialização da cultura produzem nos modos de pensar ou produzir conhecimento sobre algo ou sobre nós mesmxs. Com isso, nosso trabalho vem cartografando os possíveis efeitos de teorizações queer na pesquisa nacional em educação, buscando identificar a complexa trama por onde essas teorizações enredam-se no contexto da produção acadêmica do campo de estudos de gênero e sexualidade (dissidentes).

Embora seja possível observar o crescente número de pesquisas brasileiras do campo das Ciências Humanas e Sociais que adotam as contribuições da teoria queer na promoção de reflexões em torno dos corpos, gêneros e sexualidades em diversos contextos socioculturais, não há como negar que é relativamente recente a chegada dessa teoria ao Brasil. No entanto, uma série de estudos inspirados pelas teorizações queer, abrangendo temas diversos e formas distintas de (re)interpretar a expressão queer no campo educacional brasileiro, vêm sendo publicados. Nesse campo, vale destacar os seguintes trabalhos: 
Tabela 1: Fluxos cartográficos dos efeitos das teorizações queer na pesquisa nacional com/sobre gênero e sexualidade na educação

\begin{tabular}{|c|c|c|}
\hline $\begin{array}{c}\text { Desdobramentos do } \\
\text { queer }\end{array}$ & Principais articulações teóricas & Referências \\
\hline \multirow{2}{*}{$\begin{array}{c}\text { Educação rizomática } \\
\text { Proposta de uma educação discutida por Borba e Lima (2014) a partir } \\
\text { das contribuições de Deleuze e da teoria queer. }\end{array}$} & $\begin{array}{c}\text { BORBA, Rodrigo; LIMA, Fátima. Por uma } \\
\text { educação rizomática: sobre as potências queer, } \\
\text { a política menor e as multiplicidades. Revista } \\
\text { Periódicus, Salvador, v. 1, n. 2, p. 1-14, 2014. }\end{array}$ \\
\hline $\begin{array}{c}\text { Embichamento do } \\
\text { currículo }\end{array}$ & $\begin{array}{c}\text { Expressão criada por Sussekind e Reis (2015), a partir dos estudos } \\
\text { com os cotidianos, com a intenção de discutir questões curriculares } \\
\text { em resposta à heteronormatividade. As pesquisas com os cotidianos } \\
\text { buscam captar, no campo empírico, "seu dinamismo, seus } \\
\text { enredamentos, seus pequenos acontecimentos [...] para o encontro } \\
\text { do imprevisível, do incontrolável, do diverso, do singular que também } \\
\text { fazem parte da vida cotidiana e de aprendizagem sobre o mundo." } \\
\text { (OLIVEIRA, l., 2007, p. 122-123) }\end{array}$ & $\begin{array}{c}\text { SUSSEKIND, Maria Luiza; REIS, Graça Franco da } \\
\text { Silva. Currículos-como-experiências- vividas: } \\
\text { um relato de embichamento nos cotidianos } \\
\text { de uma escola na cidade do Rio de Janeiro. } \\
\text { Currículo Sem Fronteiras, v. 15, n. 3, p. 614-625, } \\
\text { set./dez. 2015. }\end{array}$ \\
\hline
\end{tabular}




\begin{tabular}{|c|c|c|}
\hline Currículo queer & $\begin{array}{l}\text { Para Louro, “Uma pedagogia e um currículo queer se distinguiriam } \\
\text { de programas multiculturais bem intencionados, onde as diferenças } \\
\text { (de gênero, sexuais ou étnicas) são toleradas ou são apreciadas como } \\
\text { curiosidades exóticas. Uma pedagogia e um currículo queer estariam } \\
\text { voltados para o processo de produção das diferenças e trabalhariam, } \\
\text { centralmente, com a instabilidade e a precariedade de todas as } \\
\text { identidades." (2001, p. 550, grifos dx autorx). } \\
\text { Silva, J.; Silveira e Costa visam, "por meio de uma bricolagem teórica } \\
\text { entre elementos da teoria queer e dos estudos curriculares de } \\
\text { inspiração pós-crítica, problematizar a estrutura binária e normalizante } \\
\text { do currículo, estranhando-o e desestabilizando os seus cânones } \\
\text { normalizadores, subvertendo-o, para, assim, pensá-lo a partir de um } \\
\text { perspectiva queer." (2016, p. 147-148, grifos dxs autorxs). }\end{array}$ & $\begin{array}{l}\text { LOURO, Guacira Lopes. Teoria Queer - uma } \\
\text { política pós-identitária para a educação. Revista } \\
\text { Estudos Feministas, Florianópolis, v. 9, n. 2, p. } \\
541-553,2001 \text {. } \\
\text { SILVA, João Paulo de Lorena; SILVEIRA, Ederson } \\
\text { Luís; COSTA, Leonard Cristy Souza. A teoria } \\
\text { queer e os muros da escola: tessituras entre } \\
\text { práticas e (des)normalizações. Textura, Canoas, } \\
\text { v. } 18, \text { n. 38, p. 143-161, set./dez. } 2016 \text {. }\end{array}$ \\
\hline Educação bicha & $\begin{array}{l}\text { Proposta por Zamboni (2016, p. 7), a educação bicha se inspira na } \\
\text { filosofia da diferença de Deleuze "para operar uma esquizoanálise da } \\
\text { bicha, que é abordada como devir e como analisador que possibilita } \\
\text { pensar diferentemente... }\end{array}$ & $\begin{array}{c}\text { ZAMBONI, Jésio. Educação bicha: uma a(na[l]) } \\
\text { rqueologia da diversidade sexual. 2016. 115f. } \\
\text { Tese (Doutorado em Educação) - Faculdade } \\
\text { de Educação, Universidade Federal do Espírito } \\
\text { Santo, Espírito Santo, } 2016 .\end{array}$ \\
\hline
\end{tabular}




\begin{tabular}{|c|c|c|}
\hline Pedagogia queer & $\begin{array}{l}\text { Para Louro, "uma pedagogia e um currículo queer'falam' a todos e } \\
\text { não se dirigem apenas àqueles ou àquelas que se reconhecem nessa } \\
\text { posição-de-sujeito, isto é, como sujeitos queer. Uma tal pedagogia } \\
\text { sugere o questionamento, a desnaturalização e a incerteza como } \\
\text { estratégias férteis e criativas para pensar qualquer dimensão da } \\
\text { existência." (2001, p. 552, grifos dx autorx). } \\
\text { César justifica o motivo pelo qual defende a pedagogia queer ao } \\
\text { argumentar: "Por que uma pedagogia queer? Para introduzir na } \\
\text { pedagogia e na educação a dúvida e a incerteza em relação à norma } \\
\text { disciplinar quanto aos saberes e aos corpos. Isto é, para dilacerar os } \\
\text { limites do pensamento e pensar o impensável. Por que na escola? } \\
\text { Porque na escola, em nome da racionalidade e da ciência, se produziu } \\
\text { uma história de normalização, exclusão e violência em torno dos } \\
\text { saberes, dos corpos e dos sujeitos." (2012, p. 352, grifo dx autorx). } \\
\text { Couto Junior, através dos trabalhos de Foucault e das contribuições de } \\
\text { pesquisadorxs que investigam sob as epistemologias queer, defende } \\
\text { "uma pedagogia queer preocupada em problematizar a forma como } \\
\text { os gêneros, as sexualidades e os corpos são classificados por inúmeros } \\
\text { atributos socialmente construídos que reforçam hierarquizações e, } \\
\text { consequentemente, desqualificações." (2016, p. 267, grifo dx autorx). }\end{array}$ & $\begin{array}{c}\text { LOURO, Guacira Lopes. Teoria Queer - uma } \\
\text { política pós-identitária para a educação. Revista } \\
\text { Estudos Feministas, Florianópolis, v. 9, n. 2, p. } \\
\text { 541-553, 2001. } \\
\text { CÉSAR, Maria Rita de Assis. A diferença no } \\
\text { currículo ou intervenções para uma pedagogia } \\
\text { queer. Educação Temática Digital, Campinas, v. } \\
\text { 14, n. 1, p. 351-362, jan./jun. 2012. } \\
\text { SILVA, João Paulo de Lorena; SILVEIRA, Ederson } \\
\text { Luís; COSTA, Leonard Cristy Souza. A teoria } \\
\text { queer e os muros da escola: tessituras entre } \\
\text { práticas e (des)normalizações. Textura, Canoas, } \\
\text { v. 18, n. 38, p. 143-161, set./dez. 2016. } \\
\text { COUTO JUNIOR, Dilton Ribeiro. Gênero, } \\
\text { sexualidade e a teoria queer na educação: } \\
\text { colocando em questão a heteronormatividade. } \\
\text { Atos de Pesquisa em Educação, Blumenau, v. 11, } \\
\text { n. 1, p. 250-270, jan./abr. 2016. } \\
\text { COUTO JUNIOR, Dilton Ribeiro; OSWALD, } \\
\text { Maria Luiza Magalhães Bastos. Em defesa de } \\
\text { uma pedagogia queer: re-imaginando corpos, } \\
\text { gêneros e sexualidades no espaço escolar. } \\
\text { Textura, Canoas, v. 18, n. 38, p. 123-142, set./ } \\
\text { dez. 2016. }\end{array}$ \\
\hline Via(da)gens queer & $\begin{array}{l}\text { Para Pocahy, “O que as via(da)gens queer nos apontam é que há mais } \\
\text { perigo nos caminhos pavimentados [...]. Talvez precisemos conceber } \\
\text { outras práticas de conhecer, como práticas sensíveis aos territórios } \\
\text { livres à experimentação e à produção de novos modos de vida, } \\
\text { outros modos de entendimento e simpatia pelo mundo." ( } 2016, \text { grifo } \\
\text { dx autorx, p. 23). A viadagem busca, estrategicamente, ressignificar } \\
\text { o termo injurioso (viado), transformando-o numa forma positiva de } \\
\text { celebrar outras estéticas de (r)existência. As viadagens queer podem } \\
\text { ser pensadas como as inúmeras possibilidades epistemológicas que } \\
\text { emergem com os estudos queer. }\end{array}$ & $\begin{array}{c}\text { POCAHY, Fernando. (Micro)políticas queer: } \\
\text { dissidências em pesquisa. Textura, Canoas, v. 18, } \\
\text { n. 38, p. 8-25, set./dez. } 2016 \text {. }\end{array}$ \\
\hline
\end{tabular}




\begin{tabular}{|c|c|c|}
\hline Pesquisa-aquendação & $\begin{array}{l}\text { De acordo com Pocahy, a pesquisa-aquendação defende "não apenas } \\
\text { a necessidade de outros modos de conhecer [...], mas interpelando } \\
\text { a pesquisa em outra disposição para dar corpo teórico às suas } \\
\text { experimentações e fazendo uma dobra sobre o que pensamos que é } \\
\text { conhecer, desaquendando os fascismos epistemológicos e as tirarias } \\
\text { normativas." (2013, p. 231). } \\
\text { Sobe o trabalho de Pocahy (2013), Uziel (2013) esclarece que o termo } \\
\text { "aquendar" busca "ranger a Psicologia em 'Pesquisa-aquendação'. } \\
\text { Derivas de uma epistemologia libertina, fazendo-a debater pelo avesso } \\
\text { do que ele chama de hetero ou homonormas. As preocupações } \\
\text { epistemológica e metodológica fazem transbordar o texto que se } \\
\text { inspira em Foucault e autores da teoria Queer." (UZIEL, 2013, p. 12, } \\
\text { grifos dx autorx). }\end{array}$ & $\begin{array}{l}\text { UZIEL, Anna Paula. Prefácio. In: TEIXEIRA } \\
\text { FILHO, Fernando Silva; PERES, Wiliam Siqueira; } \\
\text { RONDINI, Carina Alexandra; SOUZA, Leonardo } \\
\text { Lemos (Org.). Queering: problematizações e } \\
\text { insurgências na psicologia contemporânea. } \\
\text { Cuiabá: EDUFMT, 2013, p. 7-13. } \\
\text { POCAHY. Fernando. “Pesquisa-aquendação”: } \\
\text { derivas de uma epistemologia libertina. } \\
\text { In: TEIXEIRA FILHO, Fernando Silva; PERES, } \\
\text { Wiliam Siqueira; RONDINI, Carina Alexandra; } \\
\text { SOUZA, Leonardo Lemos (Org.). Queering: } \\
\text { problematizações e insurgências na psicologia } \\
\text { contemporânea. Cuiabá: EDUFMT, 2013, p. } \\
\text { 213-234. }\end{array}$ \\
\hline Criança transviada & $\begin{array}{l}\text { J. Silva e Paraíso (2017) buscam articular os estudos queer, o campo } \\
\text { curricular e a educação de crianças pequenas. A partir do que } \\
\text { Preciado (2013) denomina de crianças queer, xs autorxs formulam a } \\
\text { noção de criança transviada, argumentando que "os infantis-queers } \\
\text { são capazes de efetuar no currículo um 'devir-criativo' que permite a } \\
\text { construção de novas formas de relação e um 'devir-transviado' que } \\
\text { afeta e contagia todas as crianças. Nisso reside uma possibilidade de } \\
\text { resistência importante, que consiste na recusa das formas impostas } \\
\text { de subjetividade para meninos e meninas e na construção de outros } \\
\text { modos de estar e viver as infâncias no currículo." (SILVA, J.; PARAÍSO, } \\
2017, \text { p. 2, grifo dxs autorxs). }\end{array}$ & $\begin{array}{l}\text { SILVA, João Paulo de Lorena; PARAÍSO, Marlucy } \\
\text { Alves. Bagunçando as normas de gênero: } \\
\text { crianças transviadas e a invenção de outros } \\
\text { possíveis no currículo escolar. In: SEMINÁRIO } \\
\text { INTERNACIONAL DE ESTUDOS CULTURAIS E } \\
\text { EDUCAÇÃO, 4., 2017, Canoas. Anais... Canoas: } \\
\text { ULBRA, 2017, 13p. }\end{array}$ \\
\hline
\end{tabular}




\begin{tabular}{|c|c|c|}
\hline Enviadescer & $\begin{array}{l}\text { Inspirando-se no funk transviado de Linn da Quebrada, Colling, } \\
\text { Sousa e Sena defendem que a prática do enviadescimento pode } \\
\text { auxiliar no trabalho de pesquisa envolvendo a dimensão da } \\
\text { interseccionalidade: "O que é enviadescer e qual a sua potência para } \\
\text { pensar as interseccionalidades? Para tentar responder essas questões, } \\
\text { inicialmente defenderemos que pessoas e coletivos sintonizadxs } \\
\text { com as perspectivas queer têm trabalhado com mais ênfase a } \\
\text { interseccionalidade em suas ações e políticas, pensadas aqui como } \\
\text { um artivismo das dissidências sexuais e de gênero." (2017, p. 193). } \\
\text { Somando-se a isso, elxs mostram o quanto o trabalho musical de } \\
\text { "Linn da Quebrada [...] nos ensina como enviadescer para produzir } \\
\text { interseccionalidades, ou melhor, nos provoca para pensar em como } \\
\text { é necessário incluir o enviadescer nas estratégias que almejam as } \\
\text { interseccionalidades." (COLLING; SOUSA; SENA, 2017, p. 193). }\end{array}$ & $\begin{array}{l}\text { COLLING, Leandro; SOUSA, Alexandre Nunes; } \\
\text { SENA, Francisco Soares. Enviadescer para } \\
\text { produzir interseccionalidades. In: OLIVEIRA, } \\
\text { João Manuel; AMÂNCIO, Lígia (Org.). Géneros e } \\
\text { sexualidades: interseções e tangentes. Lisboa: } \\
\text { Maiadouro, 2017, p. 193-215. }\end{array}$ \\
\hline Puta teoria & $\begin{array}{c}\text { Duque (2014, p. 86) identifica a “Teoria Queer como uma puta teoria. } \\
\text { O adjetivo 'puta' aqui é pensando a partir dos seus usos múltiplos, [...] } \\
\text { com uma ideia nada ingênua de que identidade fixa e estável ainda faz } \\
\text { todo o sentido para pensar militância e políticas públicas." }\end{array}$ & $\begin{array}{l}\text { DUQUE, Tiago. Corpo, estado e militância, ou } \\
\text { sobre aquilo que você precisa saber antes de } \\
\text { começar a ler uma puta teoria. Revista Florestan, } \\
\text { São Carlos, ano 1, n. 2, p. 67-89, nov. } 2014 .\end{array}$ \\
\hline Teoria cu & $\begin{array}{l}\text { A teoria cu formulada por Pelúcio ( } 2014 a, 2014 b, 2016) \text { advém } \\
\text { principalmente das reflexões teóricas de Paul Beatriz Preciado. Nas } \\
\text { palavras de Pelúcio (2014b, p. 37-38), “É pelo cu que chego a pensar nos } \\
\text { desafios epistemológicos do presente. Quer dizer, que quero pensar fora } \\
\text { das dicotomias excludentes que ancoram em uma pretensa naturalidade } \\
\text { do corpo e neutralidade dos órgãos 'verdades' que têm implicado em } \\
\text { perpetuação de desigualdades. É por aí também que convido quem me } \\
\text { lê a pensar. Um convite que funciona como forma de desestabilizar o } \\
\text { lugar da cabeça como metonímia para a razão ocidental.” }\end{array}$ & $\begin{array}{l}\text { PELÚCIO, Larissa. Breve história afetiva de uma } \\
\text { teoria deslocada. Revista Florestan, São Carlos, } \\
\text { ano 1, n. 2, p. 26-45, nov. 2014a. } \\
\text { PELÚCIO, Larissa. Traduções e torções ou o que } \\
\text { se quer dizer quando dizemos queer no Brasil? } \\
\text { Revista Periódicus, Salvador, v. 1, n. } 1 \text { p. 68-91, } \\
\text { 2014b. } \\
\text { PELÚCIO, Larissa. O cu (de) Preciado - } \\
\text { estratégias cucarachas para não higienizar } \\
\text { o queer no Brasil. Iberic@l: Revue D'études } \\
\text { lbériques et lbéro-américaines, Paris, n. 9, p. } \\
\text { 123-136, printemps 2016. }\end{array}$ \\
\hline
\end{tabular}




\begin{tabular}{|c|c|c|}
\hline Estudos transviados & $\begin{array}{l}\text { Expressão proposta por Bento }(2009,2014) \text { como alternativa } \\
\text { à nomeação estudos queer. Esses estudos são principalmente } \\
\text { alimentados pela necessidade de se questionar o processo de } \\
\text { patologização das identidades trans. Segundo x autorx, "Nos estudos } \\
\text { transviados os discursos médicos passam a ser analisados como } \\
\text { engrenagens discursivas que limitam a existência da diversidade dos } \\
\text { desejos, dos gêneros, das sexualidades ao âmbito das estruturas fixas } \\
\text { corpóreas. E assim se estabelece uma disputa epistemológica onde } \\
\text { o corpo passa a ser um significante com múltiplos significados, uma } \\
\text { estrutura estruturante em permanente processo de transformação." } \\
\text { (BENTO, 2014, p. 49). }\end{array}$ & $\begin{array}{l}\text { BENTO, Berenice. Apresentação. In: PELÚCIO, } \\
\text { Larissa. Abjeção e Desejo - uma etnografia } \\
\text { travesti sobre o modelo preventivo de AIDS. } \\
\text { São Paulo, SP: Editora Annablume, 2009, p. } \\
17-23 \text {. } \\
\text { BENTO, Berenice. O que pode uma teoria? } \\
\text { Estudos transviados e a despatologização das } \\
\text { identidades trans. Revista Florestan, São Carlos, } \\
\text { ano 1, n. 2, p. 46-66, 2014. }\end{array}$ \\
\hline
\end{tabular}

Fonte: Elaborado pela autora, 2017. 
Ainda que algumas das nomeações acima não tenham sido produzidas dentro do campo de estudos educacionais, como é o caso dos estudos transviados (BENTO, 2009, 2014) e da teoria cu (PELÚCIO, 2014a, 2014b, 2016), essas nomeações vêm "respingando" nas pesquisas em educação através dos trabalhos de diversxs pesquisadorxs (COUTO JUNIOR, 2016; SILVA, J.; PARAÍSO, 2017, para citar alguns). Dito isso, não há como negar que a articulação entre os efeitos das ressonâncias queer e a pesquisa nacional em educação vem possibilitando o enriquecimento do campo de estudos de gênero e sexualidade. O olhar plural da pesquisa em educação envolvendo os diversos marcadores sociais de identidade e diferença oferece possibilidades teórico-metodológicas que não partem dos mesmos pressupostos, mas apresentam algumas intenções similaridades, como a produção de inúmeras análises discursivo-desconstrucionistas (POCAHY, 2016) que buscam questionar os regimes de verdade responsáveis pelo funcionamento e manutenção da supremacia do sistema hetero[CIS]centrado.

4 OS MUITOS NOMES DO QUEER OU NOSSAS (DES)ARRUMAÇÕES CONCEITUAIS NA PESQUISA SOBRE DISSIDÊNCIAS DE GÊNERO E SEXUALIDADE

Os traços iniciais de nossa cartografia evidenciam o interessante processo criativo e irreverente utilizado pelxs pesquisadorxs brasileirxs que destacam a necessidade de se (re)pensar sobre as repercussões das epistemologias queer no contexto educacional brasileiro. Os muitos nomes possíveis do queer (re)contam histórias que produzem visões sobre temporalidades específicas, o que nos convida a reconhecê-lo "como código aberto, híbrido para ser usado" (OLIVEIRA, J., 2017, p. 1). Diferentes (re)combinações, (dis)torções e (re)apropriações teóricas buscam, de certa forma, expor os limites de uma teoria formulada no Norte global e, ao mesmo tempo, encontram alternativas e estratégias epistemológicas que possibilitem (re)pensar o queer ao Sul da linha do Equador. Conceitos e teorias, quando viajam, interagem com outros espaços culturais e linguísticos "marcados por relações de poder não idênticas àquelas de onde vieram" (LOURO, 2013, p. 63-64). Com isso, não podemos negligenciar que a teoria queer vem se constituindo "como campo de saber permeado por diversas apropriações, conflitos, dissensos e [...] como solo fértil para a criatividade" (PADILHA; FACIOLI, 2015, p. 143); criatividade essa alimentada pela necessidade de se criar epistemologias interseccionais que possam servir de importante arsenal teórico-metodológico nas investigações realizadas ao Sul da linha do Equador. 
Diante dos regimes de verdade que, historicamente, vêm sendo produzidos pela pedagogia em torno dos corpos, gêneros e sexualidades (FOUCAULT, 2014), interessa-nos pensar, no campo da educação, os efeitos engendrados pelas epistemologias queer, porque "as insubordinações queer, assim como os (trans)feminismos interseccionais e pós-modernos, desarrumam e desfazem as certezas ordinárias - denunciando os desejos de norma e aqueles movimentos mais apegados a formas de dominação" (POCAHY 2016, p. 10, grifo $\mathrm{dx}$ autorx). Pensar os possíveis efeitos das teorizações queer na pesquisa nacional com/sobre gênero e sexualidade na educação é pensar em outras possibilidades epistemológicas que possam ser potentes na denúncia contra os regimes de verdade. Com isso, nosso trabalho vem acompanhando cartografias que apontam para alargamentos discursivos sobre corpos-subjetivações (im) possíveis, reconhecendo e legitimando, para além da perspectiva binária, a forma com a qual corpos, gêneros e sexualidades são ficcionados na cultura, materializando-se discursivamente em vidas de carne e osso; vidas que buscam sentidos, desejos, vontades, alegrias...

Artigo recebido em: 23/08/2017 Aprovado para publicação em: 23/03/2018

\section{EPISTEMOLOGICAL DISSIDENCES IN BRAZIL: CARTOGRAPHY OF QUEER THEORIZATIONS IN EDUCATIONAL RESEARCH}

ABSTRACT: The aim of this paper is to map the uses and impacts of the epistemological effects of queer contributions in the educational knowledge production in Brazil. To do this, we seek to outline a (provisional) plan that might indicate part of the complex plot through which these epistemological experiments, self-proclaimed and/or interpellated as dissidents, become entangled in the context of gender and sexuality academic studies. Therefore, we are interested in promoting mappable interlocutions from our experiences as Latin American subjects - experiences marked by the intersection of several social markers of identity and difference which constitute and impel us to (re)think our everyday perceptions.

KEYwords: Gender. Sexuality. Queer epistemologies. Education. 
DISIDENCIAS EPISTEMOLÓGICAS A LA BRASILEÑA: UNA CARTOGRAFÍA DE LAS TEORIZACIONES QUEER EN LA INVESTIGACIÓN EN EDUCACIÓN

RESUMEN: La propuesta de este trabajo es mapear los usos e impactos de los efectos epistemológicos de las contribuciones queer en la producción de conocimiento en educación en Brasil. Para eso, buscamos trazar un plan (provisorio) que pueda indicar algo de la compleja trama por donde tales experimentaciones epistemológicas se enredan en el contexto de la producción académica del campo de los estudios de género y sexualidad, autoproclamadas e/o interpeladas disidentes. Con eso, nos interesa aquí suscitar interlocuciones cartográficas a partir de nuestras experiencias como sujetos latinoamericanos - experiencias marcadas por el entrecruce de diversos marcadores sociales de identidad y diferencia que nos constituyen y nos impulsan a (re)pensar nuestras experiencias cotidianas.

Palabras Clave: Género. Sexualidad. Epistemologías queer. Educación.

\section{NOTAS}

1 hooks, 2013, p. 85.

2 Epistemologia refere-se ao conjunto de teorias que fornece a base conceitual (VEIGA-NETO, 2003).

30 [cis] foi acrescentado à expressão "heterocentrado", cunhada por Preciado (2014). Cabe frisar que o uso do CIS refere-se à palavra cisgênero, utilizada para designar pessoas que se identificam com os gêneros que lhes foram atribuídos no nascimento.

4 Empregamos estrategicamente o uso do " $x$ " neste trabalho com a intenção de não enquadrar grupos de sujeitos em um determinado gênero. Caso esse recurso linguístico não fosse adotado, poderíamos cair na armadinha de reforçar o binarismo mulher/ homem, responsável por circunscrever corpos, gêneros e sexualidades na cultura do regime hetero[CIS]centrado.

5 Seguimos amparados pelo pensamento de Miskolci (2014, p. 53), que, propositalmente, adota o uso de letras minúsculas na escrita do termo aids "como recusa política de transformar a designação de uma doença, portanto um substantivo, em uma sigla cuja redação em maiúsculas colaborou para criar um pânico sexual".

6 A pesquisa de pós-doutorado, intitulada "Queer no Norte, e o que(er) ao sul da linha do Equador? Panorama da produção científica brasileira (2001-2016) sobre os desdobramentos da teoria queer no campo educacional", é financiada pelo CNPq. O projeto, desenvolvido mediante supervisão dx professorx Fernando Altair Pocahy, está articulado ao Grupo de Estudos em Gênero e Sexualidade e $(m)$ Interseccionalidades (Geni) e vinculado ao Programa de Pós-Graduação em Educação da Universidade do Estado do Rio de Janeiro (ProPEd/UERJ). 
7 Sigla da Coordenação de Aperfeiçoamento de Pessoal de Nível Superior.

8 Para maiores informações sobre os estudos com os cotidianos, ver Alves (2001) e I. B. Oliveira (2013).

\section{REFERÊNCIAS}

ALVES, N. Decifrando o pergaminho: o cotidiano das escolas nas lógicas das redes cotidianas. In: OLIVEIRA, I. B.; ALVES, N. (Org.). Pesquisa no/do cotidiano das escolas: sobre redes de saberes. Rio de Janeiro: DP\&A, 2001. p. 13-37.

BENTO, B. O que pode uma teoria? estudos transviados e a despatologização das identidades trans. Revista Florestan, São Carlos, ano 1, n. 2, p. 46-66, 2014.

. Apresentação. In: PELÚCIO, L. Abjeção e Desejo: uma etnografia travesti sobre o modelo preventivo de AIDS. São Paulo, SP: Editora Annablume, 2009, p. 17-23.

BORBA, R. Linguística queer: uma perspectiva pós-identitária para os estudos da linguagem. Revista Entrelinhas, São Leopoldo, v. 9, n. 1, p. 91-107, jan./jun. 2015.

BORBA, R.; LIMA, F. Por uma educação rizomática: sobre as potências queer, a política menor e as multiplicidades. Revista Periódicus, Salvador, v. 1, n. 2, p. 1-14, 2014.

BRYSON, M.; CASTELL, S. de. Queer pedagogy: praxis makes im/perfect. Canadian Journal of Education, Canadá, v. 18, n. 3, p. 285-305, 1993.

BUTLER, J. Alianças queer e política anti-guerra. Bagoas - Estudos Gays: gênero e sexualidades, Natal, v. 11, n. 16, p. 29-49, 2017.

Critically queer. GLQ: A Journal of Lesbian and Gay Studies, Durham, v. 1, n. 1, p. 17-32, nov. 1993.

CAMARGO, W. X. Sexualidades, esportes e Teoria Queer: inter-relações. Revista Estudos Feministas, Florianópolis, v. 16, n. 3, p. 1130-1133, set./dez. 2008.

CÉSAR, M. R. A. A diferença no currículo ou intervenções para uma pedagogia queer. Educação Temática Digital, Campinas, v. 14, n. 1, p. 351-362, jan./jun. 2012.

COELHO, S. Por um feminismo queer: Beatriz Preciado e a pornografia como pre-textos. Ex aequo, Lisboa, n. 20, p. 29-40, 2009.

COLLING, L.; SOUSA, A. N.; SENA, F. S. Enviadescer para produzir interseccionalidades. In: OLIVEIRA, J. M.; AMÂNCIO, L. (Org.). Géneros e sexualidades: interseções e tangentes. Lisboa: Maiadouro, 2017. p. 193-215.

COUTO JUNIOR, D. R. Gênero, sexualidade e a teoria queer na educação: colocando em questão a heteronormatividade. Atos de Pesquisa em Educação, Blumenau, v. 11, n. 1, p. 250-270, jan./abr. 2016. 
COUTO JUNIOR, D. R.; OSWALD, M. L. M. B. Em defesa de uma pedagogia queer: re-imaginando corpos, gêneros e sexualidades no espaço escolar. Textura, Canoas, v. 18, n. 38, p. 123-142, set./dez. 2016.

COUTO JUNIOR, D. R.; OSWALD, M. L. M. B.; POCAHY, F. Gênero, sexualidade e juventude(s): problematizações sobre heteronormatividade e cotidiano escolar. In: SEMINÁRIO NACIONAL INFÂNCIAS E JUVENTUDES NA CIDADE: UM DIÁLOGO COM A EDUCAÇÃO, 1, 2017, Vitória. Anais... Vitória: UFES: 2017.

DUQUE, T. Corpo, estado e militância, ou sobre aquilo que você precisa saber antes de começar a ler uma puta teoria. Revista Florestan, São Carlos, ano 1, n. 2, p. 67-89, nov. 2014.

FOUCAULT, M. História da sexualidade I: a vontade de saber. Tradução de Maria Thereza da Costa Albuquerque e J. A. Guilhon Albuquerque. São Paulo: Paz e Terra, 2014. hooks, b. Ensinando a transgredir: a educação como prática da liberdade. Tradução de Marcelo Brandão Cipolla. São Paulo: Editora WMF Martins Fontes, 2013.

LEWIS, E. S.; BORBA, Rodrigo; FABRÍCIO, Branca Falabella; PINTO, Diana de Souza. Introdução: Cu-irizando desde o Sul. In: LEWIS, E. S.; BORBA, R.; FABRÍCIO, B. F.; PINTO, D. S. (Org.). Queering Paradigms IVa: insurgências queer ao Sul do equador. Oxford: Peter Lang, 2017, v. 1, p. 1-12.

LOURO, G. L. Um corpo estranho: ensaios sobre sexualidade e teoria queer. 2. ed. Belo Horizonte: Autêntica, 2013.

. Teoria Queer - uma política pós-identitária para a educação. Revista Estudos Feministas, Florianópolis, v. 9, n. 2, p. 541-553, 2001.

LUGARINHO, M. C. Antropofagia crítica: para uma teoria queer em português. Revista Olhar, São Carlos, ano 12, n. 22, p. 106-112, jan./jul. 2010.

MISKOLCI, R. Um saber insurgente ao sul do Equador. Revista Periódicus, Salvador, v. 1, n. 1, p. 43-67, maio/out. 2014.

. Não ao sexo rei: da estética da existência foucaultiana à política queer. In: SOUZA, L. A.; SABATINE, T. T.; MAGALHÃES, B. R. (Org.). Michel Foucault: sexualidade, corpo e direito. São Paulo: Cultura Acadêmica, 2011, p. 47-68.

A teoria queer e a sociologia: o desafio de uma analítica da normalização. Sociologias, Porto Alegre, ano 11, n. 21, p. 150-182, jan./jun. 2009.

OLIVEIRA, I. B. Currículo e processos de aprendizagemensino: políticaspráticas educacionais cotidianas. Currículo sem Fronteiras, v. 13, n. 3, p. 375-391, set./dez. 2013.

O campo de estudos do cotidiano e sua contribuição para a pesquisa em educação. In: SCHWARTZ, C. M... [et al.] (Org.). Desafios da educação básica e pesquisa em educação. Vitória: EDUFES, 2007, p. 107-127.

OLIVEIRA, J. M. Genealogias excêntricas: os mil nomes do queer (apresentação do dossiê). Revista Periódicus, Salvador, v. 1, n. 6, p. 1-6, nov./abr. 2017. 
PADILHA, F.; FACIOLI, L.É o queer tem pra hoje? Conversando sobre as potencialidades e apropriações da Teoria Queer ao Sul do Equador (entrevista com Berenice Bento). Áskesis, São Carlos, v. 4, n. 1, p. 143-155, jan./jun. 2015.

PELÚCIO, L. Breve história afetiva de uma teoria deslocada. Revista Florestan, São Carlos, ano 1, n. 2, p. 26-45, nov. 2014a.

. Traduções e torções ou o que se quer dizer quando dizemos queer no Brasil? Revista Periódicus, Salvado, v. 1, n. 1 p. 68-91, 2014b.

. O cu (de) Preciado - estratégias cucarachas para não higienizar o queer no Brasil. Iberic@l: Revue D'études Ibériques et Ibéro-américaines, Paris, n. 9, p. 123-136, printemps, 2016.

PEREIRA, P. P. G. Queer decolonial: quando as teorias viajam. Contemporânea-Revista de Sociologia da UFSCar, São Carlos, v. 5, n. 2, p. 411-437, jul./dez. 2015.

A teoria queer e a reinvenção do corpo. Cadernos Pagu, Campinas, n. 27, p. 469-477, jul./dez. 2006.

PERES, W. S.; POCAHY, F.; CARNEIRO, N. S.; TEIXEIRA-FILHO, F. S. Transconversações queer: sussurros e gemidos lusófonos: quatro cadelas mirando a(s) Psicologia(s). Revista Periódicus, Salvador, v. 1, n. 1, p. 106-153, 2014.

POCAHY, F. (Micro)políticas queer: dissidências em pesquisa. Textura, Canoas, v. 18, n. 38, p. 8-25, set./dez. 2016.

"Pesquisa-aquendação": derivas de uma epistemologia libertina. In:TEIXEIRA FILHO, F. S.; PERES, W. S.; RONDINI, C. A.; SOUZA, L. L. (Org.). Queering: problematizações e insurgências na psicologia contemporânea. Cuiabá: EDUFMT, 2013, p. 213-234.

. Notas sobre homofobia/heterossexismo. In: PASINI, E. (Org.). Educando para a diversidade. Porto Alegre: Nuances, 2007, p. 13-16.

PRADO FILHO, K.; TETI, M. M. A cartografia como método para as ciências humanas e sociais. Barbarói, Santa Cruz, n. 38, p. 45-59, jan./jun. 2013.

PRECIADO, P. B. Manifesto contrassexual: práticas subversivas de identidade sexual. Tradução de Maria Paula Gurgel Ribeiro. São Paulo: n-1 Edições, 2014.

. Quem defende a criança queer? Jangada, Viçosa, n. 1, p. 96-99, jan./jun. 2013.

ROLNIK, S. Cartografia ou de como pensar com o corpo vibrátil. São Paulo: Núcleo de Estudos da Subjetividade da PUC-SP, 1987. Disponível em: <http://www.pucsp.br/ nucleodesubjetividade/Textos/SUELY/pensarvibratil.pdf.>. Acesso em: 13 jun 2017.

SEIDMAN, S. Queer pedagogy/queer-ing sociology. Critical Sociology, v. 20, n. 3, p. 169-176, out. 1994.

SILVA, J. P. L.; PARAÍSO, M. A. Bagunçando as normas de gênero: crianças transviadas e a invenção de outros possíveis no currículo escolar. In: SEMINÁRIO INTERNACIONAL DE ESTUDOS CULTURAIS E EDUCAÇÃO, 4., 2017, Canoas. Anais... Canoas: ULBRA, 2017, 13p. 
SILVA, J. P. L.; SILVEIRA, E. L.; COSTA, L. C. S. A teoria queer e os muros da escola: tessituras entre práticas e (des)normalizações. Textura, Canoas, v. 18, n. 38, p. 143-161, set./dez. 2016.

SOUZA, F. F.; BENETTI, F. J. Historiografando a abjeção: uma arqueografia dos Estudos queer no Brasil (1990-2000). Contemporâneos: revisa de Artes e Humanidades, n. 12, p. 1-13, nov./abr. 2015.

SUSSEKIND, M. L.; REIS, G. F. S. Currículos-como-experiências- vividas: um relato de embichamento nos cotidianos de uma escola na cidade do Rio de Janeiro. Currículo Sem Fronteiras, v. 15, n. 3, p. 614-625, set./dez. 2015.

TRUJILLO, G. Pensar desde otro lugar, pensar lo impensable: hacia una pedagogía queer. Educação e Pesquisa, São Paulo, v. 41, n. especial, p. 1527-1540, dez. 2015.

UZIEL, A. P. Prefácio. In: TEIXEIRA FILHO, F. S.; PERES, W. S.; RONDINI, C. A.; SOUZA, L. L. (Org.). Queering: problematizações e insurgências na psicologia contemporânea. Cuiabá: EDUFMT, 2013, p. 7-13.

VEIGA-NETO, A. Cultura, culturas e educação. Revista Brasileira de Educação, Rio de Janeiro, v. 23, p. 5-15, 2003.

ZAMBENEDETTI, G.; SILVA, R. A. N. Cartografia e genealogia: aproximações possíveis para a pesquisa em psicologia social. Psicologia \& Sociedade, Minas Gerais, v. 23, n. 3, p. 454-463, set./dez. 2011.

ZAMBONI, J. Educação bicha: uma a(na[I])rqueologia da diversidade sexual. 2016. 115 f. Tese (Doutorado em Educação) - Faculdade de Educação, Universidade Federal do Espírito Santo, Espírito Santo, 2016.

Dilton Ribeiro Couto Junior: Pós-doutorandx no Programa de Pós- Graduação em Educação da Universidade do Estado do Rio de Janeiro (ProPEd/UERJ), com bolsa CNPq. Membro do Grupo de Pesquisa Infância, Juventude, Educação e Cultura (IJEC) e do Grupo de Estudos em Gênero e Sexualidade e(m) Interseccionalidades (Geni).

E-mail: junnior_2003@yahoo.com.br

Fernando Altair Pocahy: Professorx da Faculdade de Educação e do Programa de Pós-Graduação em Educação da Universidade do Estado do Rio de Janeiro (ProPEd/UERJ). Líder do Grupo de Estudos em Gênero e Sexualidade e $(\mathrm{m})$ Interseccionalidades (Geni).

E-mail:pocahy@uol.com.br 
